\title{
Nanosuspension Formulation of Itraconazole Eliminates the Negative Inotropic Effect of SPORANOX® in Dogs
}

\author{
Jeff McKee • Barrett Rabinow $\cdot$ Chyung Cook • \\ Jerry Gass
}

Published online: 18 March 2010

(C) American College of Medical Toxicology 2010

\begin{abstract}
Previously, it was observed that a nanosuspension formulation of itraconazole was more efficacious and yet less acutely toxic in rats as compared with the conventional solution formulation, SPORANOX ${ }^{\circledR}$ (itraconazole) Injection. The present study compares the two formulations with respect to specifically myocardial contractility in conscious dogs. Motivation for doing so is highlighted by the black-box warning in the package insert for SPORANOX ${ }^{\circledR}$ (itraconazole) Injection, which warns of negative inotropic effects. Conscious dogs, instrumented with a high-fidelity pressure transducer in the left ventricle, were placed in a sling for dosing and cardiac monitoring. Test and control articles were administered intravenously via a peripheral vein, and left ventricular parameters were measured continuously through $60 \mathrm{~min}$ from the start of dosing. As expected, SPORANOX $^{\circledR}$ (itraconazole) Injection caused a significant reduction in myocardial contractility as determined by the contractility index. In contrast, the itraconazole nanosuspension administered at twice the dose and at twice the rate of infusion did not result in significant changes in myocardial contractility. A novel formulation technology applied to itraconazole completely prevented the negative inotropic effect observed in conscious dogs as compared with SPORANOX ${ }^{\circledR}$ (itraconazole) Injection.
\end{abstract}

Keywords Itraconazole $\cdot$ Ventricular contractility · Dog

J. McKee $(\triangle) \cdot$ B. Rabinow $\cdot$ C. Cook $\cdot$ J. Gass

Baxter Healthcare,

25212 W. Illinois Rt. 120, WG2-1S,

Round Lake, IL 60073, USA

e-mail: jeff_mckee@baxter.com

\section{Introduction}

Opportunistic fungal infections have increased very significantly over the last 35 years, in both incidence and severity with associated mortality. This has occurred as patients' immunological systems have become increasingly compromised, in response to disease states such as AIDS, cancer, and diabetes, as well as the use of more aggressive medical and surgical strategies, including life support systems, broadspectrum antibiotics, high-dose cytotoxic chemotherapy, and organ transplantation [1].

To meet this challenge, an armamentarium of newer antifungal agents has been developed, accompanied by guidelines for their use that have become ever more specific [2]. This may have encouraged clinicians to proceed with dose-intensive anticancer chemotherapy even in patients having contracted invasive fungal disease (IFD) during previous cycles of treatment. However, these patients are at high risk of recurrent IFD, often with fatal outcome. Hence, efficacy of antifungal agents in secondary prophylaxis is being reported. In this context, the older but familiar triazole, itraconazole, was surprisingly shown to be equally effective as the more recently developed caspofungin in preventing second episodes of IFD [3]. Itraconazole has frequently been used owing to its activity against clinically relevant fungal pathogens. The intravenous dosage form of this drug has been recommended by the Infectious Disease Society of America for use in empirical antifungal treatment for patients with febrile neutropenia that is resistant to broad-spectrum antibiotic therapy [4]. Indeed, geographical usage of itraconazole for this indication is expanding [5]. Revised guidelines for the usage of itraconazole for this indication, as well as in aspergillosis have recently appeared $[2,6]$. 
In cases where drugs are used empirically or prophylactically rather than for treatment of confirmed infection, it is essential to consider the safety profile of the drug [7]. While amphotericin is effective for many fungal strains, its adverse event profile especially to kidneys reduces its potential use. In contrast, fluconazole has emerged as a relatively safe antifungal drug, albeit with a much narrower spectrum of activity. As a result, its use has increased significantly, accompanied, however, by the appearance of fluconazole-resistant candidal strains $[8,9]$.

Hence, there is a need to reconcile the need for reduced toxicity and yet enhanced efficacy. As precedent, successful application of liposome delivery technology to amphotericin $\mathrm{B}$ has resulted in a much safer agent, although renal toxicity is still an issue [10]. Applying novel drug delivery technology to itraconazole would be advantageous because of its relative safety particularly for the kidneys, its activity against candidiasis, and applicability to aspergillosis [11]. It is in this context that a nanosuspension formulation of itraconazole is considered.

Our previous publication focused on a reformulated injectable dosage form of the antifungal agent itraconazole [12]. It was observed that the nanosuspension formulation was more efficacious than the conventional solution formulation. This was attributed to altered pharmacokinetics (PK). By virtue of the biodistribution of nanoparticles, plasma levels were initially quite low in comparison with the typically high plasma levels with the solution form because the nanoparticles were quickly phagocytosed by the fixed macrophages of the monocyte phagocytic system (MPS). Over a period of days, the drug was slowly released from this depot. Because of the reduced plasma Cmax (maximum concentration) of this newer approach, acute toxicity was much lower as compared with the solution dosage form. This permitted a much greater amount of drug to be dosed. The parameter that best correlates with efficacy for this class of drugs is area under the concentration time curve (AUC)/minimum inhibitory concentration [13]. Since more drug could be administered coupled with sustained release from the MPS depot, the AUC was increased, despite the Cmax being reduced, and therefore the efficacy was significantly enhanced. Fungal colony count in a target tissue was reduced, and animal models infected with itraconazole-resistant organisms could be successfully treated, permitting significantly enhanced survival.

The advantage of the enhanced efficacy observed with the itraconazole nanosuspension formulation, which was attributed to altered pharmacokinetics, could be extended further by demonstrating reduced toxicity compared to the conventional solution formulation. Motivation for doing so is highlighted by the black-box warning in the SPORANOX ${ }^{\circledR}$ package insert, which stipulates, "Congestive Heart Failure: When itraconazole was administered intrave- nously to dogs and healthy human volunteers, negative inotropic effects were seen. If signs or symptoms of congestive heart failure occur during administration of SPORANOX ${ }^{\circledR}$ (itraconazole) Injection, continued SPORANOX ${ }^{\circledR}$ use should be reassessed $[14,15]$." The mechanism underlying the negative inotropic effect of itraconazole remains to be elucidated.

\section{Methods}

Preparation of Itraconazole Nanosuspension

The procedure, utilizing NANOEDGE Technology, has been described previously [16]. Briefly, within a sterilized nine-glove isolator, a solution of itraconazole (Wyckoff) and Poloxamer 188 (BASF) in $N$-methyl-2pyrrolidone (ISP/Pharmasolve) was added to an aqueous solution of sodium deoxycholate (Sigma Aldrich) and glycerin to induce rapid crystallization. This suspension was then homogenized; solvent was removed by successive centrifugation cycles, and the suspension was rehomogenized and filled into vials at a concentration of $10 \mathrm{mg} / \mathrm{ml}$ itraconazole. Mean particle size for multiple 12-1 batches and $d_{99}$ (particle size below which $99 \%$ of the volume of the suspension lies) were measured with a LA920 laser light scattering analyzer (Horiba Instruments). Zeta potential $(\zeta)$ was determined with a ZetaPALS (Brookhaven Instruments, electrode AQ471), with a sample suspension matrix identical to that of the medium of the nanosuspension.

\section{Test and Control Articles}

The test articles were SPORANOX ${ }^{\circledR}$ (itraconazole) Injection (Ortho Biotech) and $1 \%(w / v)$ itraconazole injectable suspension, $9.61 \mathrm{mg} / \mathrm{ml}$ (Baxter Healthcare Corporation, Deerfield, IL, USA). Each milliliter of SPORANOX ${ }^{\circledR}$ (itraconazole) Injection contains $10 \mathrm{mg}$ of itraconazole, solubilized by hydroxypropyl- $\beta$-cyclodextrin $(400 \mathrm{mg}$ ) as a molecular inclusion complex, with $3.8 \mu$ hydrochloric acid, $25 \mu \mathrm{l}$ propylene glycol, and sodium hydroxide for $\mathrm{pH}$ adjustment to 4.5 , in water for injection. The SPORANOX ${ }^{\circledR}$ was reconstituted per the package insert, resulting in a final itraconazole concentration of approximately $3.33 \mathrm{mg} / \mathrm{ml}$ and a hydroxypropyl- $\beta$-cyclodextrin concentration of approximately $133 \mathrm{mg} / \mathrm{ml}$. The control articles were hydroxypropyl$\beta$-cyclodextrin $\left(\mathrm{KLEPTOSE}^{\circledR}\right.$, Pyrogen Free, Roquette America, Inc., Keokuk, IA, USA) and $0.9 \%$ Sodium Chloride Injection, USP (Baxter Healthcare Corporation, Deerfield, IL, USA). Using depyrogenated glassware, a 45\% solution of hydroxypropyl- $\beta$-cyclodextrin was prepared in Water for Injection, USP, and diluted with $0.9 \%$ Sodium 
Chloride, USP, to achieve a final concentration of approximately $133 \mathrm{mg} / \mathrm{ml}$, which was equivalent to the concentration of hydroxypropyl- $\beta$-cyclodextrin in reconstituted SPORANOX ${ }^{\circledR}$. The solution of hydroxypropyl- $\beta$ cyclodextrin was filtered through a sterile $0.2-\mu \mathrm{m}$ filter prior to administration.

\section{Test System}

All animal care and use procedures were approved by the institution's animal care and use committee and were conducted in accordance with USDA Regulations, 9 CFR Parts 1, 2, and 3 and the Guide for the Care and Use of Laboratory Animals [17, 18]. Male beagle dogs (approximately 8 to 10 months old and 8.6 to $11.4 \mathrm{~kg}$ at the time of testing) were obtained from Ridglan Research Farms, Inc., Mt. Horeb, WI, USA. The dog was selected as the test system based upon the black-box warning for SPORANOX ${ }^{\circledR}$ (itraconazole) Injection, indicating that negative inotropic effects have been observed in dogs. Animals were quarantined for at least 7 days prior to the study, and only dogs showing no signs of clinical illness were used in this study. Dogs received water ad libitum and a standard canine laboratory diet once daily.

\section{Experimental Design}

The experimental design is summarized in Table 1.

\section{Experimental Protocol}

Dogs were anesthetized to effect with isoflurane in a 2:1 ratio of nitrous oxide and oxygen. A MIKRO-TIP ${ }^{\circledR}$ pressure transducer (Millar Instruments, Inc., Houston, TX, USA) was placed into the left ventricle via the left carotid artery and connected to a data acquisition and analysis system (Modular Instruments, Inc., West Chester, PA, USA). Following anesthetic recovery, conscious dogs were placed in a sling for dosing and cardiac monitoring. Test and control articles were administered intravenously via a peripheral vein using an infusion pump. Left ventricular parameters were measured continuously and tabulated at 10-s intervals before (baseline), during, and after dosing through $60 \mathrm{~min}$ from the start of dosing, but only a single 10 -s interval is reported prior to dosing (time $0 \mathrm{~min}$ ) and at 10,20,30, and $60 \mathrm{~min}$ from the start of dosing. Measured left ventricular parameters included systolic pressure, end diastolic pressure, developed pressure (systolic minus end diastolic), $\mathrm{dP} / \mathrm{dt}+$ (rate of pressure development per unit time), and contractility index (maximum $\mathrm{dP} / \mathrm{dt}+$ divided by developed pressure). Left ventricular $\mathrm{dP} / \mathrm{dt}+$ and contractility index are two measures of cardiac inotropy.

\section{Statistical Analysis}

The SAS ${ }^{\circledR}$ procedure named MIXED was used for the statistical analyses. The following group comparisons were performed at each postbaseline time point for each parameter: saline vs. nanosuspension, hydroxypropyl- $\beta$-cyclodextrin vs. SPORANOX $^{\circledR}$, and SPORANOX ${ }^{\circledR}$ vs. nanosuspension. Baseline (time $0 \mathrm{~min}$ ) was used as a covariate in the analysis of the postdosing time points. Statistical tests of overall group effect and pairwise comparisons of interest were performed at the $\alpha$ level of 0.05 .

\section{Results}

Physical Characterization and Stability of the Itraconazole Nanosuspension

The zeta potential of the itraconazole nanosuspension was $-30.55 \pm 2.90 \mathrm{mV}$. For four 12-1 batches, mean particle size and standard deviation (SD) measured at $5^{\circ} \mathrm{C}$ over 24 months was $0.581 \pm 0.018 \mu \mathrm{m}$. Over this same interval, the $\mathrm{d}_{99}$ and SD were $2.234 \pm 0.094 \mu \mathrm{m}$. At $25^{\circ} \mathrm{C}$ over 6 months, mean particle size and SD were $0.620 \pm$ $0.040 \mu \mathrm{m}$, and $\mathrm{d}_{99}$ and SD were $2.310 \pm 0.291 \mu \mathrm{m}$. Also, $\mathrm{pH}(7.5)$ and osmolality (258 mosmol/l) were stable.

Table 1 Experimental design

\begin{tabular}{|c|c|c|c|c|c|}
\hline Group & Article & Dose (mg/kg) & Infusion rate, $\mathrm{mg} / \mathrm{kg} / \mathrm{min}(\mathrm{ml} / \mathrm{kg} / \mathrm{h})$ & Infusion duration (min) & Number \\
\hline 1 & $0.9 \%$ saline & $\mathrm{N} / \mathrm{A}^{\mathrm{a}}$ & $\mathrm{N} / \mathrm{A}^{\mathrm{a}}(6)$ & 40 & 5 \\
\hline 2 & Hydroxypropyl- $\beta$-cyclodextrin & $800^{\mathrm{b}}$ & $20^{\mathrm{b}}(9)$ & 40 & 3 \\
\hline 3 & SPORANOX $^{\circledR}$ (itraconazole) Injection & $20^{\mathrm{c}}$ & $0.5^{\mathrm{c}}(9)$ & 40 & 5 \\
\hline 4 & Itraconazole nanosuspension & $40^{\mathrm{c}}$ & $1^{\mathrm{c}}(6)$ & 40 & 5 \\
\hline
\end{tabular}

N/A not applicable

${ }^{\text {a }}$ Dogs received a dose volume and a volume infusion rate similar to group 4

${ }^{\mathrm{b}}$ Equivalent to the dose and rate of hydroxypropyl- $\beta$-cyclodextrin administered to the SPORANOX ${ }^{\circledR}$ group

${ }^{\mathrm{c}}$ Itraconazole 
Myocardial Contractility in Dogs

The effects of test and control articles on left ventricular $\mathrm{dP} / \mathrm{dt}+$ are depicted in Fig. 1. The administration of $20 \mathrm{mg} / \mathrm{kg}$ SPORANOX ${ }^{\circledR}$ at $0.5 \mathrm{mg} / \mathrm{kg}$ per minute produced a steady decline in left ventricular $\mathrm{dP} / \mathrm{dt}+$ throughout the infusion period, continuing after dosing was completed through the end of the experiment. The administration of hydroxypropyl- $\beta$-cyclodextrin, the solubilizer and molecular inclusion complex in SPORANOX ${ }^{\circledR}$, at an equivalent dose $(\mathrm{mg} / \mathrm{kg})$ and rate of infusion $(\mathrm{mg} / \mathrm{kg} / \mathrm{min})$ as compared with SPORANOX ${ }^{\circledR}$ did not cause any change in left ventricular $\mathrm{dP} / \mathrm{dt}+$. The difference in left ventricular $\mathrm{dP} / \mathrm{dt}+$ between SPORANOX ${ }^{\circledR}$ and hydroxypropyl- $\beta$-cyclodextrin was statistically significant $(p<0.05)$ at all time points. These data suggest that the lower left ventricular $\mathrm{dP} / \mathrm{dt}+$ associated with SPORANOX ${ }^{\circledR}$ was due solely to the itraconazole, not hydroxypropyl- $\beta$-cyclodextrin. The administration of itraconazole as a nanosuspension, at twice the dose $(40 \mathrm{mg} / \mathrm{kg})$ and at twice the infusion rate $(1 \mathrm{mg} / \mathrm{kg} / \mathrm{min})$ as compared to SPORANOX ${ }^{\circledR}$, resulted in lower $(p<0.05)$ left ventricular $\mathrm{dP} / \mathrm{dt}+$ through $30 \mathrm{~min}$ as compared to salinetreated animals but returned to baseline prior to the end of the 40-min infusion. Although statistically significant, a decrease in ventricular $\mathrm{dP} / \mathrm{dt}+$ of approximately $1,000 \mathrm{mmHg} / \mathrm{s}$ in the nanosuspension group was considered slight in

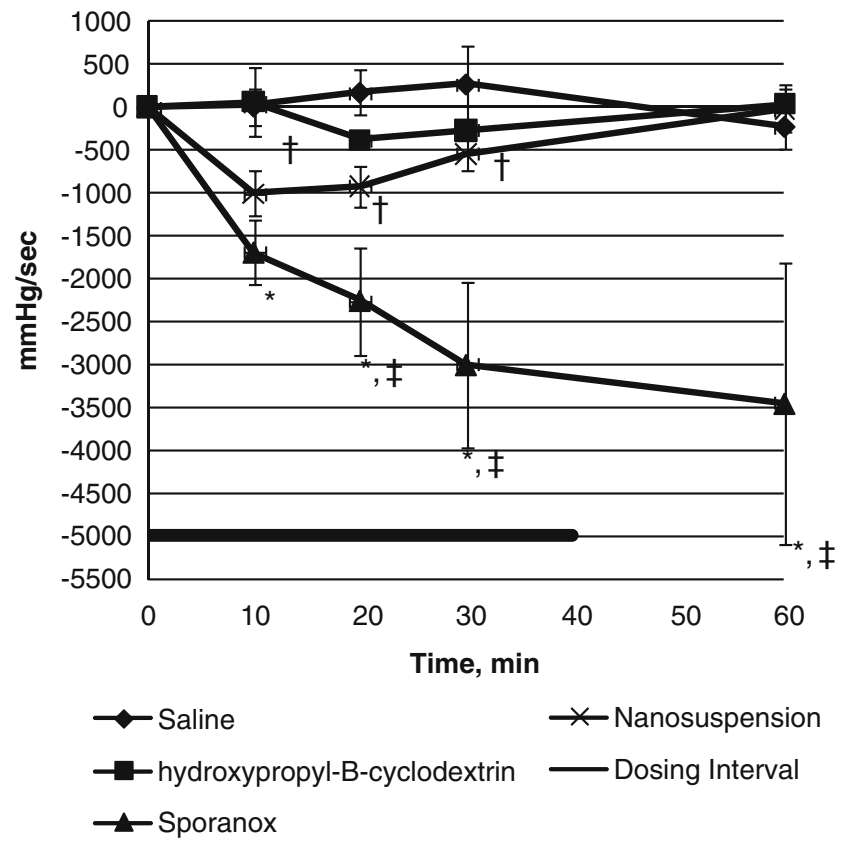

Fig. 1 Left ventricular $\mathrm{dP} / \mathrm{dt}+$ in conscious dogs. Test and control articles were administered at time 0 through $40 \mathrm{~min}$. Values represent the mean \pm SEM $(n=3-5)$. *Significantly different hydroxypropyl- $\beta$ cyclodextrin vs. SPORANOX ${ }^{\circledR}(p<0.05)$; † significantly different saline vs. nanosuspension $(p<0.05)$; tsignificantly different SPORANOX $^{\circledR}$ vs. nanosuspension $(p<0.05)$ this conscious instrumented model as ventricular $\mathrm{dP} / \mathrm{dt}+$ fluctuated $\pm 500 \mathrm{mmHg} / \mathrm{s}$ around average baseline values prior to dosing. Most notable was the observation that left ventricular $\mathrm{dP} / \mathrm{dt}+$ in the SPORANOX ${ }^{\circledR}$-treated group was lower $(p<0.05)$ than the itraconazole nanosuspension group at all time points except at $10 \mathrm{~min}$.

The effects of test and control articles on left ventricular contractility index are illustrated in Fig. 2. The administration of SPORANOX ${ }^{\circledR}$ produced a steady decline in contractility index throughout the infusion period continuing to decline after dosing was completed through the end of the experiment. The administration of hydroxypropyl- $\beta$ cyclodextrin at an equivalent dose $(\mathrm{mg} / \mathrm{kg})$ and rate of infusion $(\mathrm{mg} / \mathrm{kg} / \mathrm{min})$ as compared with SPORANOX ${ }^{\circledR}$ did not cause any change in contractility index. The difference in contractility index between SPORANOX ${ }^{\circledR}$ and hydroxypropyl- $\beta$-cyclodextrin was significant $(p<0.05)$ at all time points. These data suggest that the lower contractility index associated with SPORANOX ${ }^{\circledR}$ was due solely to the itraconazole and not hydroxypropyl- $\beta$ cyclodextrin. When itraconazole was administered as a nanosuspension at twice the dose and at twice the infusion rate as compared to SPORANOX ${ }^{\circledR}$, no significant change in contractility index was observed as compared to salinetreated animals except at $30 \mathrm{~min}$. Although the difference between the itraconazole nanosuspension group and the saline group was statistically significant $(p=0.0425)$ at $30 \mathrm{~min}$, based on the magnitude of the difference and its single occurrence, this difference was not considered toxicologically significant. The salient observation was that left ventricular contractility index in the SPORANOX ${ }^{\circledR}$ treated group was lower $(p<0.05)$ at all time points as compared with the itraconazole nanosuspension.

\section{Discussion}

Under the conditions of this study, the administration of $20 \mathrm{mg} / \mathrm{kg}$ SPORANOX ${ }^{\circledR}$ at $0.5 \mathrm{mg} / \mathrm{kg}$ per minute produced a significant, negative inotropic effect in conscious dogs, consistent with the black-box warning associated with SPORANOX ${ }^{\circledR}$. The negative inotropic effect was attributed to the active pharmaceutical ingredient itraconazole since the administration of hydroxypropyl- $\beta$-cyclodextrin, at an equivalent exposure as compared with SPORANOX ${ }^{\circledR}$, did not affect myocardial contractility. In contrast, when itraconazole was administered as a nanosuspension at twice the dose $(40 \mathrm{mg} / \mathrm{kg})$ and at twice the infusion rate $(1 \mathrm{mg} / \mathrm{kg}$ per minute), no such reduction in myocardial contractility was observed as determined by the contractility index.

Left ventricular $\mathrm{dP} / \mathrm{dt}+$ is often used as a measure of myocardial contractility. Nearly a century ago, however, it 

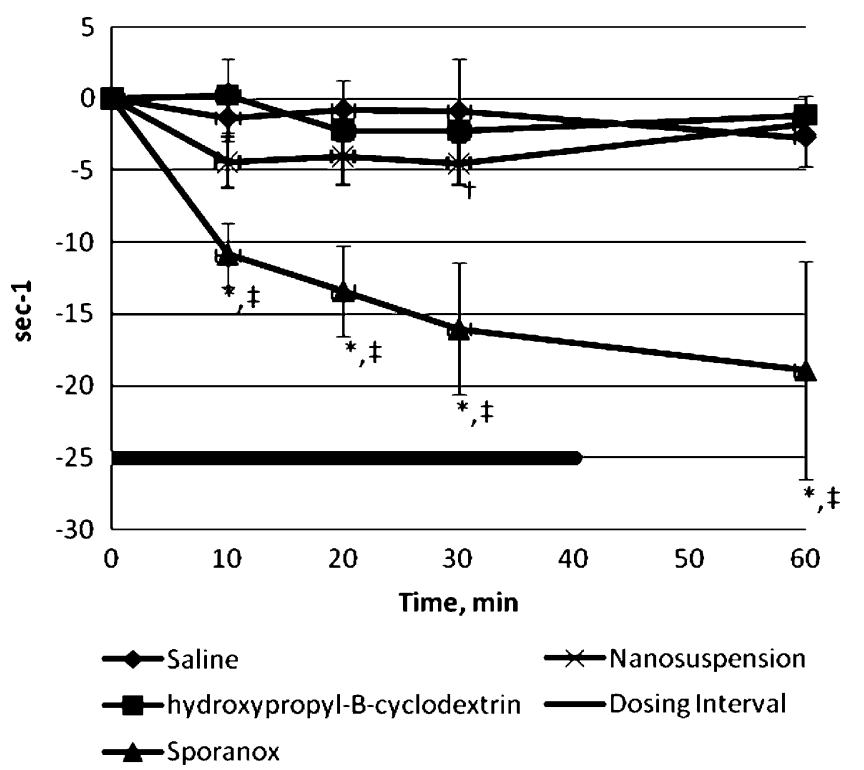

Fig. 2 Left ventricular contractility index in conscious dogs. Test and control articles were administered at time 0 through $40 \mathrm{~min}$. Values represent the mean $\pm \operatorname{SEM}(n=3-5)$. *Significantly different hydroxypropyl- $\beta$-cyclodextrin vs. SPORANOX ${ }^{\circledR}(p<0.05)$; $\uparrow$ significantly different saline vs. nanosuspension $(p<0.05)$; $\$$ significantly different SPORANOX ${ }^{\circledR}$ vs. nanosuspension $(p<0.05)$

was demonstrated in the intact dog heart that ventricular pressure development during contraction is dependent, in part, on ventricular end diastolic volume (cardiac preload) just prior to contraction [19]. This relationship states that as ventricular end diastolic volume increases (or decreases) pressure development also increases (or decreases) and was described later as the Frank-Starling relationship. Left ventricular $\mathrm{dP} / \mathrm{dt}+$, therefore, may be a misleading indicator of myocardial contractility if ventricular end diastolic volume is not taken into consideration. In contrast, contractility index does take into account the influence of ventricular end diastolic volume on pressure development and as such is a superior index of myocardial contractility as compared with ventricular $\mathrm{dP} / \mathrm{dt}+$. Although left ventricular end diastolic volume was not directly measured in the present study, left ventricular end diastolic pressure was used as a surrogate marker.

The cardiotoxicity of SPORANOX ${ }^{\circledR}$ as compared with the itraconazole nanosuspension formulation found in the present study is consistent with the greater acute toxicity of the solution formulation found in rats. There, rapid death was observed in one of five animals dosed with $30 \mathrm{mg} / \mathrm{kg}$ SPORANOX ${ }^{\circledR}$ and all animals dosed at $80 \mathrm{mg} / \mathrm{kg}$. In contrast, no deaths occurred in any of the ten animals per group dosed with the itraconazole nanosuspension at levels of $40,80,160$, and $320 \mathrm{mg} / \mathrm{kg}$ [12].

The lack of cardiotoxicity associated with the nanosuspension formulation of itraconazole is attributed to a lower plasma concentration of free itraconazole available to cardiac tissue. Although plasma concentrations of free itraconazole were not evaluated in the present study, this is consistent with the PK found in rats in which animals administered SPORANOX ${ }^{\circledR}$ had over an order of magnitude greater plasma level of itraconazole than did nanosuspension-dosed animals within the first hour of dosing [12]. The first hour is emphasized here because it corresponds to the greatest difference in left ventricular contractility index observed in the present study.

The lower plasma concentration of free itraconazole associated with the nanosuspension formulation has been attributed to its rapid preferential uptake by cells of the MPS, particularly the spleen. Evidence to support this is based on pathological observations following an acute toxicity study in rats with the nanosuspension formulation [12]. Seven days after a single intravenous dose of $320 \mathrm{mg} / \mathrm{kg}$ of the nanosuspension formulation, pale, enlarged spleens were noted in all ten animals. A microscopic evaluation revealed cytoplasmic enlargement and vacuolation of splenic macrophages. Furthermore, electron microscopy demonstrated that the vacuolation was attributable to the presence of drug crystals within splenic macrophages. It is hypothesized that subsequent dissolution of the drug crystals from within the cells to the extracellular space, down a concentration gradient, provides a sustained-release drug depot effect. The finding of initial sequestration by the MPS, followed by slow release, is generally found for intravenously administered nanoparticulate dosage forms [20].

Despite the significantly reduced plasma itraconazole levels, it was found that nanosuspension-formulated itraconazole is significantly more effective than SPORANOX ${ }^{\circledR}$ in rats challenged with candidiasis [12]. For the nanosuspension formulation, the kidney drug levels were significantly higher than SPORANOX ${ }^{\circledR}$, leading to much reduced candida colony counts in kidney tissue. Furthermore, nanosuspension-treated rats survived a challenge with a lethal dose of an itraconazole-resistant strain of candida, while all SPORANOX ${ }^{\circledR}$ animals died. The reduced acute toxicity of the nanosuspension, due to lower peak plasma drug levels, permitted significantly increased dosing of the drug as a nanosuspension. Effectively, the AUC of the drug, the relevant pharmacological parameter for this drug class, could be significantly increased simply by changing the PK of the drug. This example demonstrates how the therapeutic index of a drug can be significantly increased by alteration of the PK, in the case where toxicity and efficacy are mediated by different parameters, Cmax and AUC, respectively.

In addition to mitigating cardiotoxicity, a ready-to-dose nanosuspension formulation of itraconazole has additional advantages over SPORANOX ${ }^{\circledR}$ including reducing the risk of medication errors and simplifying the jobs of medical personnel. SPORANOX ${ }^{\circledR}$ requires correct preparation and 
administration to ensure maximal safety and efficacy. Proper preparation requires the transfer of the full contents of the SPORANOX ${ }^{\circledR}$ ampule $(25 \mathrm{ml}$ at $10 \mathrm{mg} / \mathrm{ml})$ to $0.9 \%$ Sodium Chloride Injection $(50 \mathrm{ml})$ to achieve a concentration of itraconazole of $3.33 \mathrm{mg} / \mathrm{ml}$. The health care professional is then required to remove $15 \mathrm{ml}$ of the solution and discard prior to administering to the patient. All of these steps can be eliminated with a ready-to-dose nanosuspension of itraconazole. At an infusion rate of $1 \mathrm{ml} / \mathrm{min}$, it will require an hour to infuse the required $60-\mathrm{ml}(200 \mathrm{mg})$ dose of SPORANOX ${ }^{\circledR}$. Based on the myocardial contractility results in the present study, however, the infusion duration required to deliver the recommended dose of itraconazole may be able to be decreased with a nanosuspension formulation without the negative inotropic effects.

In summary, a nanosuspension formulation of itraconazole lacks the negative inotropic effects associated with SPORANOX ${ }^{\circledR}$ for Injection as demonstrated in conscious dogs. In addition, there is the potential for the itraconazole nanosuspension formulation to mitigate medication errors as compared to SPORANOX ${ }^{\circledR}$ for Injection.

Acknowledgements We would like to thank Audrey Hutchcraft for her contributions which have helped to support the generation of this manuscript. This work was supported in full by Baxter Healthcare Corporation.

\section{References}

1. Pfaller M, Wenzel R (2003) The epidemiology of fungal infections. In: Elias E, McGinnis M, Pfaller M (eds) Clinical mycology. Elsevier Science, New York

2. Pappas P, Kauffman C, Andes D et al (2009) Clinical practice guidelines for the management of candidiasis: 2009 update by the Infectious Diseases Society of America. Clin Infect Dis 48:503535

3. Vehreschild J, Sieniawski M, Reuter S et al (2009) Efficacy of caspofungin and itraconazole as secondary antifungal prophylaxis: analysis of data from a multinational registry. Int $\mathbf{J}$ Antimicrob Agents 34:446-450

4. Pappas P, Rex J, Sobel J et al (2004) Guidelines for treatment of candidiasis. Clin Infect Dis 38:161-189
5. Ohta K, Kosaka S, Nakao Y et al (2009) Efficacy and safety of intravenous itraconazole as empirical antifungal therapy for persistent fever in neutropenic patients with hematological malignancies in Japan. Int J Hematol 89:649-655

6. Walsh T, Anaissie E, Denning D et al (2008) Treatment of aspergillosis: clinical practice guidelines of the Infectious Diseases Society of America. Clin Infect Dis 46:327-360

7. Hughes W, Armstrong D, Bodey G et al (1997) Guidelines for the use of antimicrobial agents in neutropenic patients with unexplained fever. Clin Infect Dis 25:551-573

8. Revankar S, Kirkpatrick W, McAtee R et al (1996) Detection and significance of fluconazole resistance in oropharyngeal candidiasis in human immunodeficiency virus-infected patients. J Infect Dis $174: 821-827$

9. Wingard J, Merz W, Rinaldi M et al (1991) Increase in Candida krusei infection among patients with bone marrow transplantation and neutropenia treated prophylactically with fluconazole. New Engl J Med 325:1274-1277

10. Walsh T, Teppler H, Donowitz G et al (2004) Caspofungin versus liposomal amphotericin B for empirical antifungal therapy in patients with persistent fever and neutropenia. New Engl J Med 351:1391-1402

11. Boogaerts M, Winston D, Bow E et al (2001) Intravenous and oral itraconazole versus intravenous amphotericin B deoxycholate as empirical antifungal therapy for persistent fever in neutropenic patients with cancer who are receiving broad-spectrum antibacterial therapy. Ann Intern Med 135:412-422

12. Rabinow B, Kipp J, Papadopoulos P et al (2007) Itraconazole IV nanosuspension enhances efficacy through altered pharmacokinetics in the rat. Int J Pharm 339:251-260

13. Andes D (2003) In vivo pharmacodynamics of antifungal drugs in treatment of candidiasis. Antimicrob Agents Chemother 47:11791186

14. SPORANOX ${ }^{\circledR}$ (itraconazole) Injection package insert. Revised March 2009

15. Ahmad S, Singer S, Leissa B (2001) Congestive heart failure associated with itraconazole. The Lancet 357:1766-1767

16. Kipp J, Wong J, Doty M et al (2003) Microprecipitation method for preparing submicron suspensions. US Patent No. 6607784 B2

17. Code of Federal Regulations (2009) Title 9: Animals and animal products. Chapter 1, subchapter A, parts 1, and 3: Animal welfare. Jan 1, 2009.

18. Institute of Laboratory Animal Resources (US), Committee on Care and Use of Laboratory Animals (1996) Guide for the care and use of laboratory animals. Public Health Service, US Dept. of Health and Human Services, Bethesda

19. Patterson S, Piper H, Starling E (1914) The regulation of the heartbeat. J Physiol 48(6):465-513

20. Moghimi M, Hunter C, Murray C (2001) Long-circulating and target-specific nanoparticles: theory to practice. Pharmacol Rev 53:283-318 